\title{
CORRIGENDUM
}

\section{Dose-response effects of raw potato starch on small-intestinal escape, large-bowel fermentation and gut transit time in the rat}

By J. C. Mathers, Helen Smith and Sophie Carter

Volume 78 (1997), Number 6

Figure 2, page 1023

Please replace Figure 2 with the following:

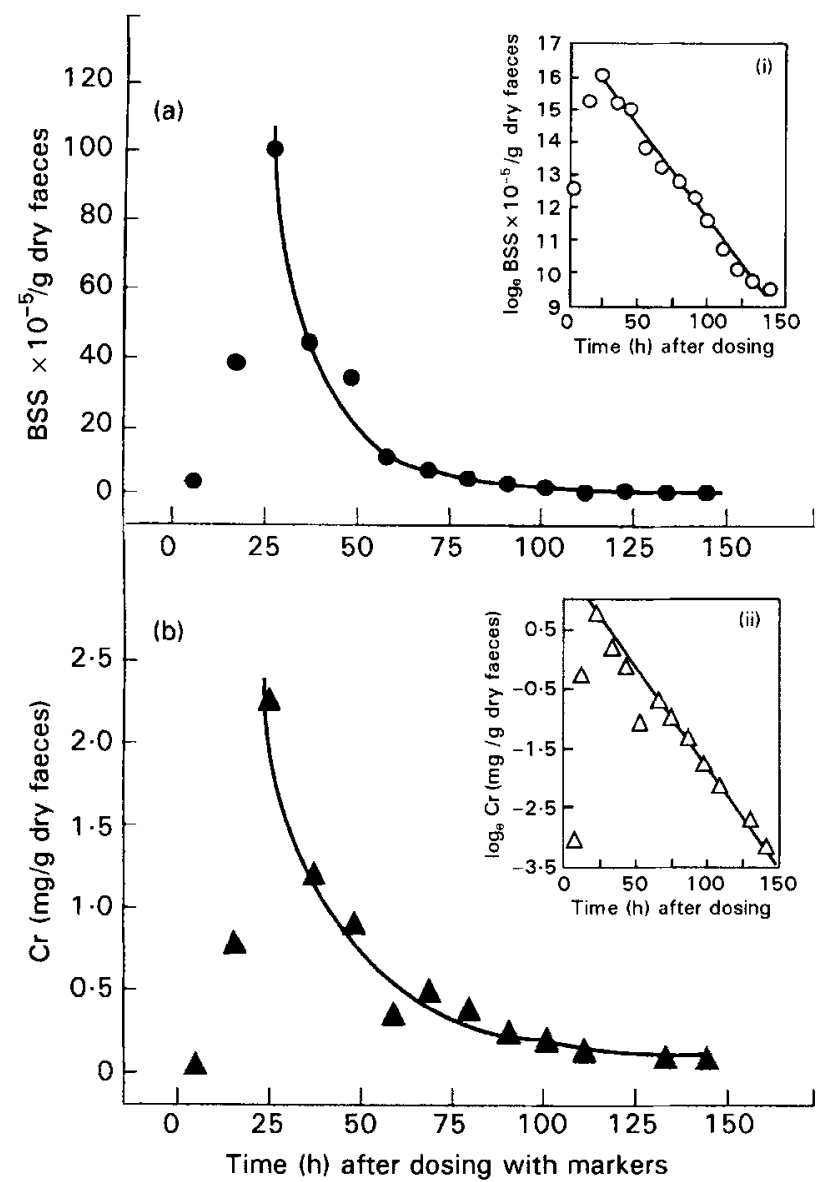

Fig. 2. Concentrations of (a) Bacillus stearothermophilus spores (BSS) (- - ) and (b) chromium-EDTA ( $-\mathbf{A})$ in faeces following a single oral dose of the markers given in a test meal. This example is for a rat fed on diet PS2 (see Table 1). The inset panels illustrate the extraction of a rate constant $\left(k_{1}\right)$ from the descending portions of the natural logarithm of the marker concentration-with-time curves for (i) BSS $(\mathrm{O}-\mathrm{O})$ and (ii) chromium-EDTA $(\triangle-\triangle)$. 